\title{
Short Technical Report Probe Generation Directly from Small Numbers of Cells for DNA Microarray Studies
}

C.C. Xiang, M. Chen,

O.A. Kozhich ${ }^{1}$, Q.N. Phan, J.M. Inman ${ }^{1}$, Y. Chen ${ }^{2}$, and M.J. Brownstein

NIMH/NIH, Bethesda, ${ }^{1}$ National Cancer Institute at Frederick, Frederick, and ${ }^{2}$ National Human Genome Research Institute, NIH, Bethesda, MD, USA

\footnotetext{
ABSTRACT

Recently, we described a technique that allows us to prepare probes for expression profiling from 0.5-1 $\mu \mathrm{g}$ RNA without template or signal amplification. However, we were unable to use this method to study cells harvested by needle biopsy, cell sorting, or laser capture microdissection. Here we give a new protocol for amplifying RNA with multiple reaction cycles and preparing fluorescent probes from approximately 10 cells. We use random 9-mers with a T3 RNA polymerase recognition sequence on the $5^{\prime}$ end for every round of $c D N A$ synthesis except the first. The latter is primed with oligo(dT) with a T7 RNA polymerase recognition sequence on the $5^{\prime}$ end. Results were highly reproducible and reliable, and the products generated using our method seemed comparable to those produced using the RiboAmp RNA kit when both were used to do two cycles of amplification. To test our method's utility, we lysed cells directly into reverse transcription buffer containing RNase inhibitor and performed three rounds of RNA amplification. The expression profiles of mouse $C 2$ and NIH 3 T3 cells obtained with 11 232-element arrays using amplified RNAs were similar to those seen when probes were prepared from unamplified templates.
}

\section{INTRODUCTION}

DNA microarrays permit one to look at the expression of thousands of genes in parallel, and they have been used for numerous basic and clinical studies in the last few years $(4,8,9,13)$. To take full advantage of such arrays, one would like to be able to profile small numbers of cells or even single cells. Labeling probes by direct labeling of total RNA requires a minimum of about $20 \mu \mathrm{g}$ template, and analysis of small tissue samples is impossible using this method $(6,7)$. We have recently described a technique that allows us to prepare probes from $0.5-1 \mu \mathrm{g}$ RNA without signal or template amplification (15). For many experiments, this is adequate, but to study small samples, it is not.

In the past several years, techniques have been developed that are much less RNA intensive than ours $(1,2,10,11)$. These methods depend on one or two rounds of template amplification, and they still require a good deal of starting material. For example, Wang et al. (14) described a procedure that allowed them to label $10 \mathrm{ng}$ total RNA (made from a concentrated stock solution) with two rounds of RNA amplification mediated by T7 RNA polymerase (T7). Since a typical mammalian cell has only 5-10 pg RNA, this corresponds to the amount of RNA in 1000-2000 cells. Recently, Puskas et al. (12) compared two RNA amplification methods-T7-based in vitro transcription (one round amplification starting with $3 \mu \mathrm{g}$ total RNA) and PCR-based amplification ( 25 cycles starting with $50 \mathrm{ng}$ total RNA) - to a standard direct labeling protocol. They found that both amplification techniques give reproducible microarray data, but they were not without problems. The false-positive and false-negative rates were higher than those seen with the conventional labeling protocol.

To the best of our knowledge, no quantitative array studies have been undertaken with fewer than 1000 cultured or laser-captured cells. Typically, one round of T7 amplification gives a 100to 1000-fold increase in RNA, and two rounds give a 10000 -fold increase $(5,14)$. Thus, as suggested earlier, two rounds should not generate enough template to label probe using the technique that we described earlier this year (15). Instead, three or more rounds of amplification would be needed. Here we show that several consecutive rounds of amplification can be performed using the T3N9 primer described above and that DNA probes prepared from approximately 10 cells give reliable expression profiles.

\section{MATERIALS AND METHODS}

\section{Microarray Fabrication}

cDNA microarrays with a total of 11232 elements were printed on polyL-lysine coated slides. The cDNAs used were provided by Bento Soares (University of Iowa, IA, USA). Plasmids were extracted from the bacteria using QIAprep ${ }^{\circledR}$ Turbo kits and a BioRobot $^{\mathrm{TM}} 8000$ (both from Qiagen, Valencia, CA, USA). The cDNA inserts were amplified with modified M13 primers (M13F, 5'-GTTGTAAAACGACGGCCAGTG-3', and M13R, 5'-CACACAGGAAACAGCTATG-3') and purified with MultiScreen ${ }^{\circledR}$ PCR plates (Millipore, Bedford, MA, USA). 
The PCR products were diluted in 50\% DMSO to an average concentration of $200 \mathrm{ng} / \mu \mathrm{L}$. These products $(5 \mu \mathrm{L}$ each) were transferred to 384-well plates (Genetix, St. James, NY, USA) and then printed using an OmniGrid ${ }^{\circledR}$ arrayer (GeneMachines, San Carlos, CA, USA). The printed slides were aged for a week and then post-processed before hybridization. For detailed descriptions of coating glass with poly-L-lysine and post-processing the printed slides, please visit http://cmgm.stanford.edu/ pbrown/mguide/index.html.

\section{RNA Sample Preparation}

Total RNA was extracted from mouse $\mathrm{C} 2$ and NIH 3 T3 cells using TRIzOL ${ }^{\circledR}$ reagent (Invitrogen, Carlsbad, CA, USA). Amplified RNAs were prepared from total RNA or from lysed cells. For total RNA, we used $1 \mu \mathrm{g}$ (in $2 \mu \mathrm{L}$ ) total RNA in the first round of amplification and $1 \mu \mathrm{g}$ amplified RNA for the second and subsequent rounds. The RNA template was added to a 0.2$\mathrm{mL}$ PCR tube containing $6 \mu \mathrm{L} 5 \times$ firststrand buffer (Invitrogen), $31 \mu \mathrm{L}$ RNase-free water (Invitrogen), and 1 $\mu L$ RNase inhibitor (Promega, Madison, WI, USA). The volume was decreased to $23 \mu \mathrm{L}$ in a vacuum centrifuge (SpeedVac ${ }^{\circledR}$; Thermo Savant, Holbrook, NY, USA) before initiating the first-strand cDNA synthesis.

Cells were first collected and washed in cold $1 \times$ PBS. Then, they were counted and diluted to final concentrations of 5000 or 50000 cells/mL. Two microliters of cell suspension (approximately 10 or 100 cells) were added to a $0.5-\mathrm{mL}$ tube containing $6 \mu \mathrm{L} 5 \times$ first-strand buffer (Invitrogen), $31 \mu \mathrm{L}$ RNase-free water, and $1 \mu \mathrm{L}$ RNase inhibitor. The cells were lysed in a cup sonicator (Misonix, Farmingdale, NY, USA), and the particulate matter was pelleted in a microcentrifuge at $16000 \times g$ for $15 \mathrm{~min}$ at $4^{\circ} \mathrm{C}$. The supernatant was transferred to a $0.2-\mathrm{mL}$ PCR tube, and the volume was reduced to $23 \mu \mathrm{L}$ as described above. DNase I (0.5 $\mu \mathrm{L}$; Ambion, Austin, TX, USA) was added, and the genomic DNA was digested at $37^{\circ} \mathrm{C}$ for $30 \mathrm{~min}$, following which the DNase was inactivated at $75^{\circ} \mathrm{C}$ for $5 \mathrm{~min}$.

For first-strand synthesis, $1 \mu \mathrm{L}$ of a $100 \mathrm{pmol} / \mu \mathrm{L}$ solution of T7dT primer
(5'-GGCCAGTGAATTGTAATACGACTCACTATAGGGAGGCGGTTTTTTTTTTTTTTTTTTTT-3'; Operon, Alameda, CA, USA) was added to 23 $\mu \mathrm{L}$ RNA- or DNase-treated cell lysate. The RNA was denatured at $70^{\circ} \mathrm{C}$ for 10 min and chilled on ice for $10 \mathrm{~min}$. dNTPs $(1 \mu \mathrm{L} 10 \mathrm{mM}$; Amersham Biosciences, Piscataway, NJ, USA), $3 \mu \mathrm{L}$ $0.1 \mathrm{mM}$ DTT (Invitrogen), and $2 \mu \mathrm{L}$ SuperScript II $^{\mathrm{TM}}$ reverse transcriptase (Invitrogen) were added to the tubes and incubated at $42^{\circ} \mathrm{C}$ for $2 \mathrm{~h}$. For the second-strand cDNA synthesis, $81 \mu \mathrm{L}$ RNase-free water, $30 \mu \mathrm{L} 5 \times$ secondstrand buffer (Invitrogen), $3 \mu \mathrm{L} 10 \mathrm{mM}$ dNTPs, $1 \mu \mathrm{L}$ E. coli DNA ligase (Invitrogen), $4 \mu \mathrm{L} E$. coli DNA polymerase I (Invitrogen), and $1 \mu \mathrm{L}$ RNase H (Invitrogen) were added to bring the total volume to $150 \mu \mathrm{L}$, and the tubes were incubated at $16^{\circ} \mathrm{C}$ for $2 \mathrm{~h}$. At the end of this time, $2 \mu \mathrm{L}$ T4 DNA polymerase (Invitrogen) were added, and the samples were incubated at $16^{\circ} \mathrm{C}$ for $5 \mathrm{~min}$. Phase Lock Gel ${ }^{\mathrm{TM}}$ (Eppendorf, Westbury, NY, USA) and phenol-chloroform-IAA (Invitrogen) were used to extract the cDNA products, and Microcon-30 ${ }^{\circledR}$ columns (Millipore) were then employed to concentrate and further purify them. The cDNAs were dried with a SpeedVac and resuspended in $4.5 \mu \mathrm{L}$ RNase-free water. RNA was transcribed from the DNA template with a MEGA Script ${ }^{\mathrm{TM}}$ T7 reagents (Ambion), according the manufacturer's instructions, and purified with an RNeasy ${ }^{\circledR}$ Mini kit (Qiagen).

For second and subsequent rounds of amplification, we used a T3N9 primer (5'-GCGCGAAATTAACCCTCACTAAAGGGAGAGGGNNNNNNNNN-3'; Invitrogen) to drive first-strand cDNA synthesis. Second-strand cDNA synthesis and in vitro transcription were performed as described above.

When the RiboAmp ${ }^{\mathrm{TM}}$ kit (Arcturus, Mountain View, CA, USA) was employed to amplify purified samples of total RNA, the reagents were used according to the manufacturer's directions.

\section{Probe Labeling with Amine- Modified Random Primers}

Probes were synthesized from $5 \mu \mathrm{g}$ total RNA, $2 \mu \mathrm{g}$ amplified material produced from purifed RNA, or the en- tire product from lysed cells. The labeling method was described in detail earlier (15). Briefly, the RNA $(15.5 \mu \mathrm{L})$ was combined with amine-modified random primer (AC6T hexamer; Sigma-Genosys, The Woodlands, TX, $\mathrm{USA} ; 2 \mu \mathrm{g} / \mu \mathrm{L}, 2 \mu \mathrm{L})$ and RNase inhibitor $(5 \mathrm{U} / \mu \mathrm{L}, 1 \mu \mathrm{L})$, incubated at $70^{\circ} \mathrm{C}$ for $10 \mathrm{~min}$, and chilled on ice for $10 \mathrm{~min}$. The primer/RNA solution was then added to the RT mixture $[6 \mu \mathrm{L} 5 \times$ first-strand buffer; $0.6 \mu \mathrm{L} 50 \times$ aminoallyl dUTP/dNTPs (25 mM dATP, dGTP, and $\mathrm{dCTP}, 15 \mathrm{mM}$ dTTP, and $10 \mathrm{mM}$ aminoallyl dUTP); $3 \mu \mathrm{L}$ 0.1 M DTT; 2 $\mu \mathrm{L}$ SuperScript II reverse transcriptase] and incubated at $42^{\circ} \mathrm{C}$ for $2 \mathrm{~h}$. The reaction was terminated with $10 \mu \mathrm{L} 0.5$ $M$ EDTA, and the RNA was hydrolyzed with $10 \mu \mathrm{L} 1 \mathrm{M} \mathrm{NaOH}$ at $65^{\circ} \mathrm{C}$ for $30 \mathrm{~min}$. The solution was neutralized with $10 \mu \mathrm{L} 1 \mathrm{M} \mathrm{HCl}$, and MinElute ${ }^{\mathrm{TM}} \mathrm{PCR}$ purification kits (Qiagen) were used to purify the products. These were concentrated to $9 \mu \mathrm{L}$ in a SpeedVac, and then $1 \mu \mathrm{L} 1 \mathrm{M}$ sodium bicarbonate, $\mathrm{pH}$ 9.3, was added to the cDNA solution, followed by $14.5 \mu \mathrm{L}$ dye solution [NHS-ester Cy3 or Cy5 (Amersham Biosciences), $62.5 \mu \mathrm{g} / \mu \mathrm{L}$ in DMSO]. The resulting solution was mixed by pipetting it up and down several times; the tubes were wrapped in aluminum foil and incubated at room temperature for $1 \mathrm{~h}$ on an orbital shaker (USA Scientific, Ocala, FL, USA). The labeling reaction was stopped with 4.5 $\mu \mathrm{L} 4 \mathrm{M}$ hydroxylamine hydrochloride (Sigma, St. Louis, MO, USA). The contents of the tubes were mixed, briefly centrifuged, and incubated for $30 \mathrm{~min}$ at room temperature in the dark. The probes were purified using QIAquick $^{\mathrm{TM}}$ PCR purification kits (Qiagen). The products were partially dried in a vacuum centrifuge, and the volumes were adjusted to $23 \mu \mathrm{L}$ with water. Then, $4.5 \mu \mathrm{L} 20 \times \mathrm{SSC}, 2 \mu \mathrm{L}$ poly(A) $(10 \mathrm{mg} / \mathrm{mL})$, and $0.6 \mu \mathrm{L} 10 \%$ SDS were added, and the probes were denatured at $100^{\circ} \mathrm{C}$ for $2 \mathrm{~min}$. The solutions were pipetted onto arrays, coverslips were applied, and the slides were placed in a hybridization chamber (Corning, Corning, NY, USA). They were incubated in a $65^{\circ} \mathrm{C}$ water bath for 16-24 h, washed with $0.5 \times \mathrm{SSC}, 0.01 \%$ $\mathrm{SDS}$, followed by $0.06 \times \mathrm{SSC}$ at room temperature (10 min each). The slides 
were then placed in 50-mL Falcon ${ }^{\circledR}$ tubes and centrifuged for $5 \mathrm{~min}$ at $200 \times$ $g$ at room temperature.

\section{Array Scanning and Data Analysis}

The arrays were scanned with a GenePix ${ }^{\circledR}$ 4000A scanner (Axon, Foster City, CA, USA) at $10 \mu \mathrm{m}$ resolution. The PMT voltage settings were varied to obtain the maximum signal intensities with less than $1 \%$ probe saturation. The resulting images were analyzed using IPLab (Fairfax, VA, USA) and ArraySuite (NHGRI, Bethesda, MD, USA) software. The $\log _{2}$ mean intensity was calculated to generate scatter plots for the self/self comparisons of probes prepared from amplified $\mathrm{C} 2$ RNA. To compare data from different rounds of amplification with $\mathrm{T} 3 \mathrm{~N} 9$ and to compare our method to the Arcturus RiboAmp method, C2/3T3 ratios were determined, all of the ratios were assigned quality scores, and elements with quality lower than 1 were removed from the dataset $(3,15)$. The remaining ratios were then ranked from lowest to highest. The top $10 \%$ and bottom $10 \%$ of ranked genes were selected, and only those that were concordant in duplicate experiments with unamplified total RNA were considered "true" outliers. Then, the top and bottom $10 \%$ of ranked genes identified in each amplification experiment were compared to the list of genes obtained with unamplified probes.

\section{RESULTS AND DISCUSSION}

The amplification method we used is diagrammed in Figure 1. Complementary DNA synthesis from total RNA is primed by oligo-dT, on the $5^{\prime}$ end of which is a T7 RNA polymerase promoter sequence (T7dT). The RNA strands are replaced with DNA by RNase H, DNA polymerase I, and $E$. coli DNA ligase. Antisense RNA is then transcribed from the dsDNA template by T7 RNA polymerase. Up to this point, our method is rather similar to others that have been described in the literature. Now it diverges from them. DNA synthesis from transcribed RNA is primed by random 9-mers with T3 RNA polymerase promoter sequences on their $5^{\prime}$ ends (T3N9). dsDNA is prepared as described above, and RNA is generated by T3 RNA polymerase. Steps 4 and 5 can be repeated as many times as one wants. The resulting products are not $3^{\prime}$-end biased.

First, we compared our amplification method to the one marketed by Arcturus, the RiboAmp RNA kit, which is recommended by the manufacturer for amplifying RNA from lasercaptured cells. Since the instructions provided indicate that the kit can only be used for two rounds of amplification, we used it this way and employed our method to do two rounds (one T7dT primed and one T3N9 primed) as well. We amplified both C2 and 3T3 RNAs and labeled $2 \mu \mathrm{g}$ amplified product as well as $5 \mu \mathrm{g}$ unamplified $\mathrm{C} 2$ and $3 \mathrm{~T} 3$ RNA. C2 probes from the Arcturus amplification, our amplification, and the unamplified samples were combined with the corresponding $3 \mathrm{~T} 3$ probes, and

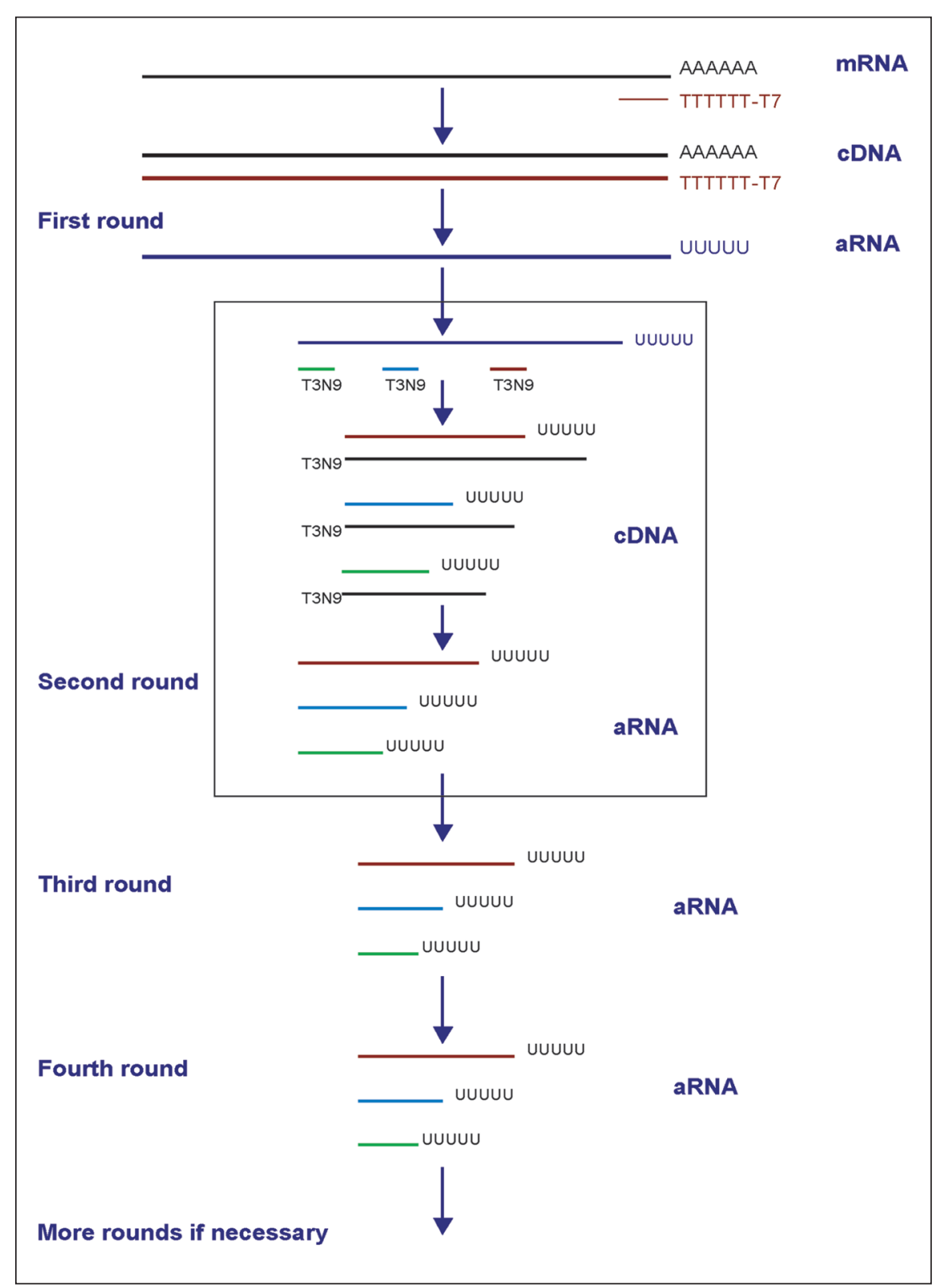

Figure 1. RNA amplification strategy. First-strand synthesis of the cDNA used for the first-round amplification is primed with T7dT. This is followed by second-strand replacement reactions (see Materials and Methods). For the second and subsequent rounds of amplification, reverse transcription of the first strand is primed with T3N9. This step can be repeated several times. 


\section{MicROARRAY Technologies}

the probe pairs were hybridized to 11232 -element cDNA arrays. After the data were filtered and normalized, 544 genes were identified as "true outliers" based on three experiments with unamplified total RNA (see the "Array Scanning and Data Analysis" section for details). Using probes prepared from RNAs that had undergone two rounds of amplification, we found 394 consistent outliers using our method and 397 with the Arcturus RiboAmp method. In the first round of amplification, our method and the Arcturus method gave similar results - 445 and 446 consistent outliers, respectively. Of these, about $18 \%$ were not on the list of "true outliers" discovered when unamplified RNA was used. This result was encouraging, but as mentioned earlier, two rounds of synthesis would surely not permit us to profile small numbers of cells, and we wondered whether we could safely do additional cycles.

To answer this question, we amplified two samples of C2 RNA in parallel with one another a total of six times. At the end of each synthetic cycle, we made Cy5- and Cy3-labeled probes from the products, combined these, and used them to develop 11232 -element arrays. As shown in Figure 2, analysis of the signals observed revealed excellent correlation coefficients at each consecutive step.

This was not a terribly stringent analysis, however, and we designed a more rigorous one. We amplified both C2 and 3T3 RNAs up to six times using T3N9 to drive first-strand synthesis in each round except the first, when T7dT was employed instead. Probes were made from amplified C2 (Cy3-labeled) and 3T3 (Cy5-labeled) RNAs following each round of amplification. These

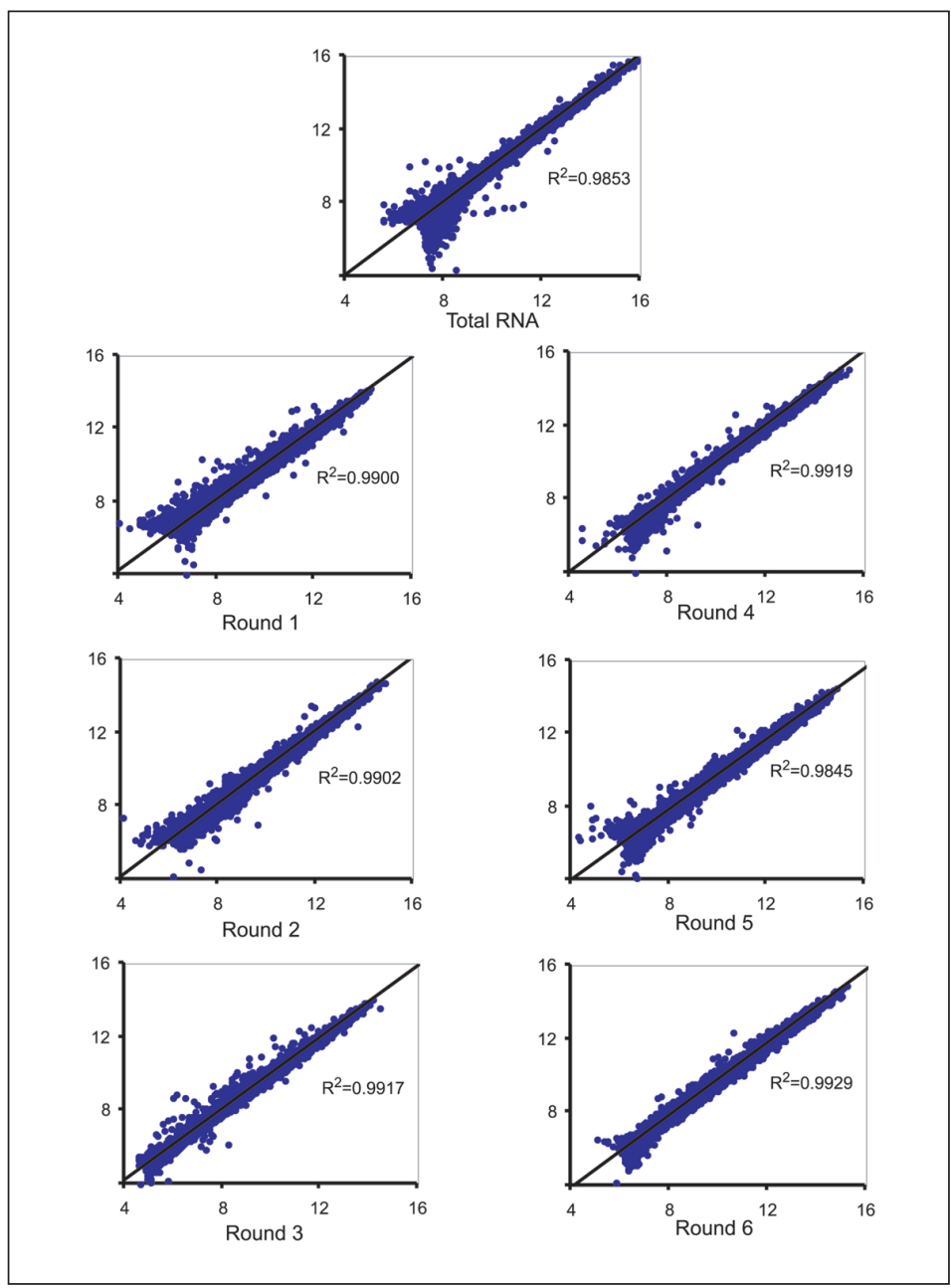

Figure 2. Reproducibility of RNA amplification with T3N9: self versus self experiments. A single RNA sample was divided in half and amplified up to six rounds. Following each round, the samples were used to prepare Cy3- or Cy5-labeled probes, which were combined and applied to an 11323 -element array. DNA used as a template for the first round of amplification was synthesized from $1 \mu \mathrm{g}$ mouse C2 total RNA. The reverse transcription was primed by T7dT. Subsequent rounds of amplification were primed by T3N9 (see Materials and Methods and Figure 1). Probes made from unamplified total RNA $\left(\mathrm{R}^{2}=0.9853\right)$, and RNA that had been amplified $1,2,3,4,5$, and 6 times gave excellent correlation coefficients $-\mathrm{R}^{2}=0.9900,0.9902,0.9917$, $0.9919,0.9845$, and 0.9929 , respectively.

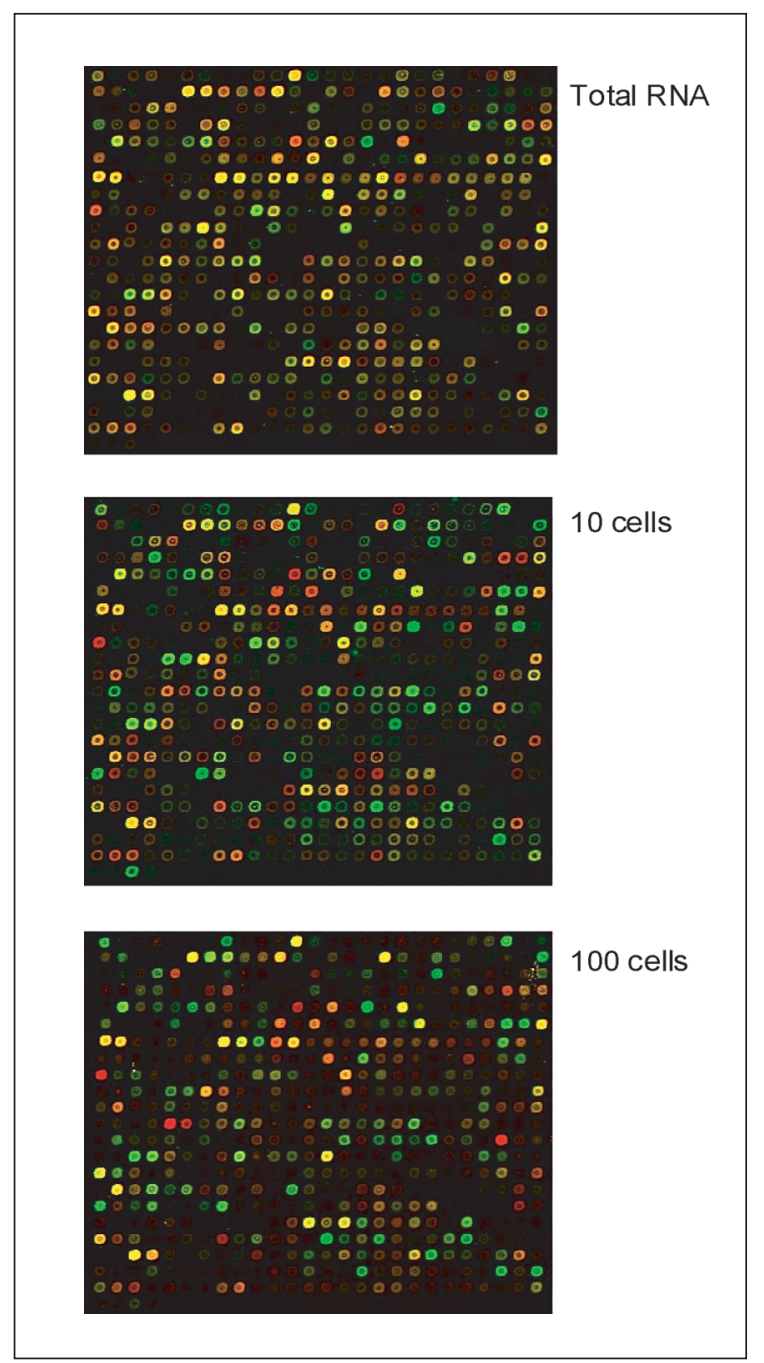

Figure 3. Probes from a small number of cells. Partial images of 11232 -element arrays. Cy5-labeled probe was made from $5 \mu \mathrm{g}$ mouse 3T3 total RNA used as reference. Amplified and unamplified C2 RNAs were labeled with Cy3. Top, Probes made from $5 \mu \mathrm{g}$ each mouse $\mathrm{C} 2$ and $3 \mathrm{~T} 3$ total RNA; middle, Cy3 probe made from 10 mouse $\mathrm{C} 2$ cells after three rounds of RNA amplification; bottom, $\mathrm{Cy} 3$ probe made from 100 mouse $\mathrm{C} 2$ cells after three rounds of RNA amplification. 
were combined, and 11 232-element arrays were developed with probes from unamplified total RNAs and amplified RNAs. The filtered ratios were ranked as described above. In duplicate experiments with unamplified RNA, 602 "true outliers" were found. When arrays were developed using probes made from RNAs that had been amplified 1 to 6 times, respectively, 513, 512, 498469,442 , and 404 concordant outliers were found. Thus, after four rounds, we were still able to detect $75 \%$ of "true outliers" we had seen with unamplified probes. As many other researchers have observed, a single round of amplification creates some biasthat is, the profiles obtained are quite similar when amplified and unamplified probes are compared, but not identical. In three subsequent amplification steps with T3N9, however, little additional distortion is introduced. More than $91 \%$ of the differentially expressed genes found in rounds one and four were concordant. This is not to say that products from rounds 1 and 4 are identical, even though consecutive rounds of amplification give very similar products. To compare two samples, it is best to amplify both the same number of times.

To profile 10 and 100 cells, we prepared DNase-treated lysates from mouse $\mathrm{C} 2$ cells, as described in the Materials and Methods section, and performed three rounds of amplification on the RNA in these extracts. We then made probes from the products, developed arrays with them, and compared the results to those obtained with probes made from purified $\mathrm{C} 2$ cell total RNA. As shown in Figure 3, the resulting probes gave remarkably similar results.

We conclude that the amplification method we have developed, used in tandem with the labeling technique we described earlier, can be used to make probes from a small number of cells for expression profiling. Refining the technique should allow us to study single cells.

\section{ACKNOWLEDGMENTS}

This project was partly supported by federal funds from the National Cancer Institute, National Institutes of Health, under contract no. NO1-CO-12400. The content of this publication does not necessarily reflect the views or policies of the Department of Health and $\mathrm{Hu}-$ man Services, nor does mention of trade names, commercial products, or organizations imply endorsement by the US government.

\section{REFERENCES}

1.Baugh, L.R., A.A. Hill, E.L. Brown, and C.P. Hunter. 2001. Quantitative analysis of mRNA amplification by in vitro transcription. Nucleic Acids Res. 29:e29.

2.Buchman, G.W., D.M. Schuster, and A. Rashtchian. 1993. Selective RNA amplification-a novel method using dump-containing primers and uracil DNA glycosylase. PCR Methods Appl. 3:28-31.

3.Chen, Y., V. Kamat, E.R. Dougherty, M.L Bittner, P.S. Meltzer, and J.M. Trent. 2002 Ratio statistics of gene expression levels and applications to microarray data analysis Bioinformatics 18:1207-1215.

4.DeRisi, J., L. Penland, P.O. Brown, M.L. Bittner, P.S. Meltzer, M. Ray, Y., Chen, Y.A Su, and J.M. Trent. 1996. Use of a cDNA microarray to analyse gene expression patterns in human cancer. Nat. Genet. 14:457460

5.Dixon, A.K., P.J. Richardson, R.D. Pinnock, and K. Lee. 2000. Gene-expression analysis at the single-cell level. Trends Pharmacol. Sci. 21:65-70

6.Duggan, D., M. Bitter, Y. Chen, P. Meltzer, and J. Trent. 1999. Expression profiling using cDNA microarrays. Nat. Genet. Suppl. 21:10-14.

7.Eisen, M.B. and P.O. Brown. 1999. DNA arrays for analysis of gene expression. Methods Enzymol. 303:179-205.

8.Heller, R.A., M. Schena, A. Chai, D. Shalon, T. Bedilion, J. Gilmore, D.E. Woolley, and R.W. Davis. 1997. Discovery and analysis of inflammatory disease-related genes using cDNA microarrary. Proc. Natl. Acad. Sci. USA 94:2150-2155.

9.Khan, J., R. Simon, M. Bittner, Y. Chen, S.B. Leighton, T. Pohida, P.D. Smith, Y. Jiang, et al. 1998. Gene expression profiling of alveolar rhabdomyosarcoma with cDNA microarrays. Cancer Res. 58:5009-5013.

10.Luo, L., R.C. Salunga, H. Guo, A. Bittner, K.C. Joy, J.E. Galindo, H. Xiao, K.E Rogers, et al. 1999. Gene expression profiles of laser-captured adjacent neuronal subtypes. Nat. Med. 5:117-122.

11.Phillips, J. and J.H. Eberwine. 1996. Antisense RNA amplification: a linear amplification method for analyzing the mRNA population from single living cells. Methods 10:283-288.

12.Puskas, L.G., A. Zvara, L. Hackler, Jr., and P. Van Hummelen. 2002. RNA amplification results in reproducible microarray data with slight ratio bias. BioTechniques 32:13301340 .

13.Schena, M., D. Shalon, R.W. Davis, and
P.O. Brown. 1995. Quantitative monitoring of gene expression patterns with a complementary DNA microarray. Science 270:484487

14.Wang, E., L.D. Miller, G.A. Ohnmacht, E.T. Liu, and F.M. Marincola. 2000. High-fidelity mRNA amplification for gene profiling. Nat. Biotechnol. 18:457-459.

15.Xiang, C.C., O.A. Kozhich, M. Chen, J.M. Inman, Q.N. Phan, and M.J. Brownstein. 2002. An improved method to label probes for DNA microarray work: amine-modified random primers. Nat. Biotechnol. 20:738-742.

Received 16 August 2002; accepted 4 October 2002

Address correspondence to:

Dr. Michael J. Brownstein

Laboratory of Genetics

NIMH/NHGRI

National Institutes of Health

Building 36, Room 3D06

Bethesda, MD 20892, USA

e-mail:mike@codon.nih.gov

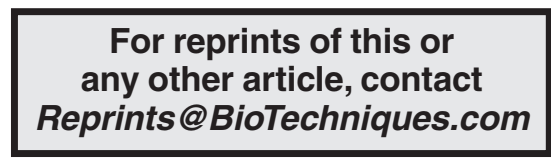

